\title{
Optimization Techniques for Transportation Problems of Three Variables
}

\author{
Mrs. Rekha Vivek Joshi, \\ ( Lecturer, Department of Mathematics, Sydenham College of Commerce and Economics, Mumbai University, \\ India)
}

\begin{abstract}
Transportation problem is considered a vitally important aspect that has been studied in a wide range of operations including research domains. As such, it has been used in simulation of several real life problems. Thus, optimizing transportation problem of variables has remarkably been significant to various disciplines. In this paper, three variables will be optimized to reduce transportation cost using four methods which will include: Northwest corner method, least cost method, Vogel method and modi method. This will mainly aim at finding the best and cheapest route on how supply will be used to satisfy demand at specific points. This will imply that, a variable cost of shipping products from suppliers to demand points will be considered.
\end{abstract}

Key words: optimization techniques, transportation problem, Northwest corner, least cost, Vogel, Modi.

\section{INTRODUCTION}

Optimization refers to the process of choosing elements considered to be the best from several alternatives that might be availed. As such, one has to solve problems with the aim of minimizing or maximizing a real function. This can be achieved via choosing values of integers or real variables from a specified set of values. This makes transportation to be considered as simply being after finding an optimal distribution plan for a certain single commodity (Ahmad 2012). When commodity supply is available at various sources, demand tends to be specified for the commodity at every destination, with transportation cost from source to destination clearly defined. In this case, the puzzle is in finding the optimal distribution plan that can minimize the overall transportation cost for product transportation from sources to destinations.

In this paper, transportation problem will be formulated as linear programming problems that will be solved using four methods ${ }^{1}$ (Atoum 2009). The MODI method is considered as being a standardized technique when it comes to obtaining optimal solution. On the other hand, Vogel is believed to be an approximation method. It usually tends to produce an optimal or near optimal initial solution. Several researches in this field determined that Vogel produces an optimum solution in almost $80 \%$ of the problems under test. Advantage of this method is that it accounts for its allocations (Ech-Cherif 2010).

In addition to the above two methods, the least cost method achieves its goals via giving more allocations to the least cost cell. Rows and columns with complete allocations are ignored as the allocation process continues (Soewono 2010). This procedure is considered to be complete on condition that all requirements for all rows and columns have satisfactorily been addressed. The Northwest corner is the forth method and it begins its allocation at the northwest corner of the matrix. It ensures that it assigns more units to each cell while putting into consideration to meet the requirement of not having more that $x+y-1$ filled cells. In this case, $x=$ number of rows while $y=$ number of columns (Tlelo-Cuautle 2010). This procedure is iterated for the remaining rows until when the requirements for all rows and columns will have been met.

\section{TRANSPORTATION METHOD}

When transportation method is employed in solving a transportation problem, the very initial step that has to be undertaken is to obtain a feasible solution satisfying demand and supply requirement (Lu 2010). Several methods will be used in this paper to obtain this initial feasible problem. As mentioned earlier in this paper, the methods to be used will include:

\subsection{Northwest corner method}

This is a method used to compute feasible solution of a transportation problem. In this method, the basic variables are usually chosen from the top left corner commonly referred to as the Northwest corner. The following steps are followed to obtain this feasible solution

\footnotetext{
${ }^{1}$ Northwest corner, Modi, Vogel and least cost method
} 
2.1.1 The first step is to locate and select the cell on the top left corner in a transportation table. This cell will have to be allocated as many units as possible. The units must be equal to the minimum between available requirements for demand and supply.

2.1.2 The next step is to adjust the numbers for demand and supply in their allocated rows and columns. The first cell in the second row will only be proceeded to, provided supply for the first row has been exhausted. Similarly, the next cell in the second column will also be proceeded to on condition that demand for the first cell has been satisfied.

2.1.3 For the allocated cells, in case any cell supply equals to demand, the next allocation can be done either in the next row or column. This procedure is looped until full allocation of the total available quantity has successfully been done to the required cells. The following example will be used in the rest of the paper to illustrate how the four mentioned methods work

\subsubsection{Example 1.0}

Mahindra manufacturers with facilities in various places have manufacturing plants in Kolkata denoted by letter K, Bangluru by letter B, and Mumbai by letter M. On a normal working day, the usual daily production for these three plants is 50 for Kolkata plant, 40 for Bangluru and 60 for Mumbai plant. In addition, this company has three warehouses located in Vadodra denoted by letter V, Chakan denoted by letter C and Nagpur by letter $\mathrm{N}$. These warehouses have a daily demand of 20 units for Vadodra, 95 units for Chakan and 35 units for Nagpur. The following table 1 gives a summary of shipping cost per unit.

TABLE 1

\begin{tabular}{|l|l|l|l|l|}
\hline & & Warehouse & N \\
\hline \multirow{3}{*}{ Plant } & & V & C & N \\
\cline { 2 - 6 } & K & 6 & 4 & 1 \\
\cline { 2 - 6 } & B & 3 & 8 & 7 \\
\cline { 2 - 6 } & M & 4 & 4 & 2 \\
\hline
\end{tabular}

Use the following methods to obtain a route that Wesonga manufacturers can use in order to minimize their total transportation cost: Northwest corner, least cost method, Vogel method and MODI method.

\subsubsection{Mathematical statement of the above transportation problem}

Mathematically, transportation can be defined as:

$\mathrm{c}_{\mathrm{q}}=$ quantity produced at the plants, $\mathrm{q}=$ plants, $\mathrm{d}_{\mathrm{p}}=$ quantity required at the warehouse, $\mathrm{p}=$ warehouses, $\mathrm{e}_{\mathrm{qp}}=$ cost of transportation for a single unit from plants to warehouses and $f_{\mathrm{qp}}=$ transported quantity from plants to warehouses.

Thus, using the Northwest corner method, the basic feasible solution can be obtained as shown in table 2 below:

TABLE 2

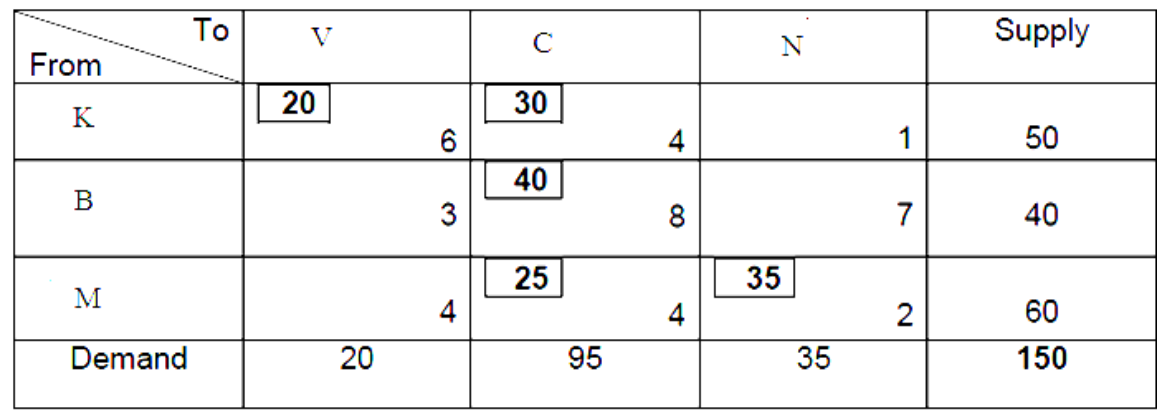

Thus, the total cost becomes: $(6 * 20)+(4 * 30)+(8 * 40)+(4 * 25)+(2 * 35)=$ Rs. 730

As per the rule of this method, this unit routing has managed to satisfy all the demand and supply requirements via entailing $5(=x+y-1=3+3-1)$.

\subsection{Least cost method}

When least cost as a method is used to compute a basic feasible solution in a transportation problem, choosing basic variables is usually done as the unit cost of transportation. To obtain this feasible solution, the following steps have to be considered and followed:

2.2.1 Locate the cell containing the smallest transportation cost per unit $\left(\mathrm{e}_{\mathrm{qp}}\right)$. In case there are more than two least costs, use the row and column that tend to correspond with the row having the least value. But in case they seem to be in the row, then the column with the lowest value will have to be selected. 
2.2.2 The value of the corresponding $\mathrm{f}_{\mathrm{qp}}$, subject to constraints in capacity and requirement will then be chosen as much as possible (Burkard 2009). Satisfying supply will imply that the row be deleted, just like satisfying demand will lead to deletion of the column (Djebbar 2009). These steps will have to be iterated so that all restrictions can be met. Table 3 below illustrates the basic feasible solution for example 1.0 using this method.

TABLE 3

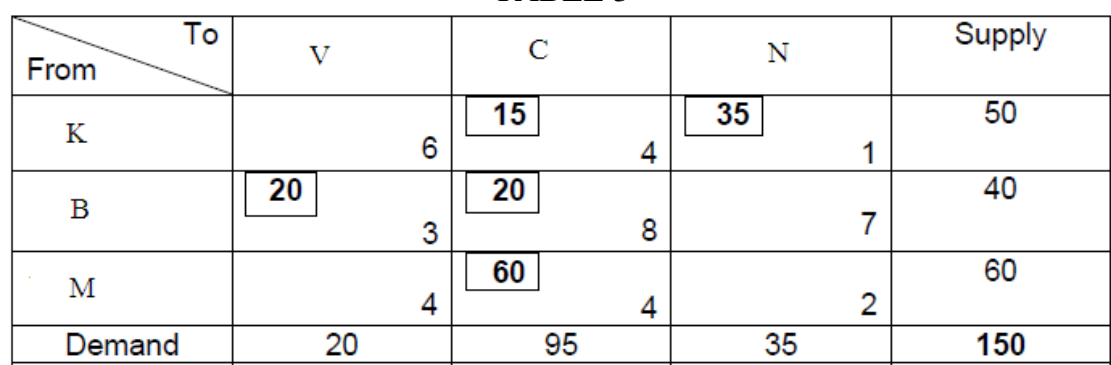

The total cost in this method will be obtained as follows:

Total cost $=(3 * 20)+(4 * 15)+(8 * 20)+(4 * 60)+(1 * 35)=$ Rs. 555

Just like in the Northwest corner method, the least cost method has also managed to satisfy demand/supply requirement as it entailed $5(=x+y-1=3+3-1)$.

\subsection{Vogel method}

This method tends to repeat procedures to compute a basic feasible solution of the transportation problem. However, some steps have to be followed while carrying out such computations. These include:

2.3.1 Two cells have to be identified ${ }^{2}$. After cell identification, the difference between these two values has to be determined and written against the corresponding row on the side of the table (Mahad 2011). This procedure has to be repeated for columns whereby the cell with the minimum transportation cost as well as the cell with the next to minimum transportation cost have to be identified in each column and their difference determined so that it can be written against the corresponding column.

2.3.2 After this, the next step is to determine the maximum difference so that in case it is located on the side of the table, maximum allotment is granted to the cell with the minimum cost of transportation in that particular column. In case the corresponding differences for two or more rows/columns are termed as being equal, the row on the very upper part of the table and the far left column should be selected (Alimohamadi 2009). This can be illustrated best as shown below in table 4 .

TABLE 4

\begin{tabular}{|c|c|c|c|c|c|c|}
\hline \multirow{2}{*}{ From ${ }^{\text {To }}$} & \multirow{2}{*}{$\mathrm{V}$} & \multirow{2}{*}{$\mathrm{C}$} & \multirow[t]{2}{*}{$\mathrm{N}$} & \multirow[t]{2}{*}{ Supply } & \multicolumn{2}{|c|}{ Repetition } \\
\hline & & & & & I & II \\
\hline $\mathrm{K}$ & 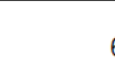 & 15 & 35 & 50 & 3 & 3 \\
\hline B & 20 & 20 & 7 & 40 & 4 & 1 \\
\hline M & 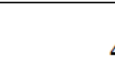 & 60 & 2 & 60 & 2 & 2 \\
\hline Demand & 20 & 95 & 35 & 150 & & \\
\hline I & 1 & 0 & 1 & & & \\
\hline II & - & 0 & 1 & & & \\
\hline
\end{tabular}

The total cost in Vogel method can be established as,

Total cost $=(3 * 20)+(4 * 15) *(8 * 20) *(4 * 60)+(1 * 35)=$ Rs. 555

Just like with the previous methods, Vogel method also managed to satisfy supply and demand requirements.

After obtaining initial solution using these first three methods, it has to pass through an optimal testing process. By definition, an optimal solution refers to a solution in which no more transportation routes can manage to reduce the total transportation cost (Chaudhuri 2011). This implies that the process of evaluating cells that are not occupied in a transportation table has to be initiated. This process is usually carried out in terms of opportunities aiming at reducing the overall transportation cost (Araghi 2009). The new set of transportation routes must then include a cell having the largest negative opportunity cost but remain unoccupied. In such

\footnotetext{
${ }^{2}$ One box having the minimum transportation cost and another one having the next to minimum transportation cost in each row
} 
cases, the forth method mentioned is considered to be the most efficient. This method is called the MODI method.

\subsection{MODI method}

To obtain this optimal solution using this method, a number of steps have to be followed. These include:

2.4.1 Using one of the earliest three methods ${ }^{3}$, determine a starting basic feasible solution. After this, the next step is to determine dual variables, $\mathrm{g}_{\mathrm{q}}$ and $\mathrm{hp}$ using $\mathrm{g}_{\mathrm{q}}+\mathrm{h}_{\mathrm{p}}=\mathrm{e}_{\mathrm{qp}}$. This will then facilitate computation of the opportunity cost as $\mathrm{i}_{\mathrm{qp}}=\mathrm{e}_{\mathrm{qp}}-\left(\mathrm{g}_{\mathrm{q}}+\mathrm{h}_{\mathrm{p}}\right)$. In case the opportunity costs for all cells not occupied are either zero or positive, the remaining solution will be the optimal solution (Putcha 2010). But if any of the unoccupied cells has a negative opportunity cost, then the resulting solution cannot be considered as the optimum solution, making further savings in transportation cost to be possible.

2.4.2 Therefore, the cell having the least negative opportunity cost but not occupied will be selected as the cell to be included in the solution to be computed next.

2.4.3 A closed loop for unoccupied selected cell is then drawn, whereby positive and negative signs are assigned on the corner points of the unoccupied cells' closed loop. The positive sign is usually placed on the cell under evaluation (Mayo 2009).

2.4.4 From here, the maximum number of units to be transported to the unoccupied cell being evaluated has to be determined. Thereby, the smallest value having a minus position on the closed loop will represent the units to be transported to the entering cell. This is the quantity that will have to be added to all cells located on the corner points of the closed loop containing a positive sign and be subtracted from negative cells, hence turning an unoccupied cell into being occupied (Turkey 2008). This procedure will have to be repeated severally until an optimum solution is obtained. This is illustrated better in table 5 as shown below:

TABLE 5

\begin{tabular}{|c|c|c|c|c|c|}
\hline From & $\mathrm{V}$ & C & $\mathrm{N}$ & Supply & $\mathrm{g}_{\mathrm{q}}$ \\
\hline $\mathrm{K}$ & 6 & $\begin{array}{ll}15 & \\
& 4\end{array}$ & 35 & 50 & $\mathrm{~g}_{1}=0$ \\
\hline B & 20 & 20 & 7 & 40 & $g_{2}=4$ \\
\hline $\mathrm{M}$ & 4 & 60 & 2 & 60 & $g_{3}=0$ \\
\hline Demand & 20 & 95 & 35 & 150 & \\
\hline $\mathrm{h}_{\mathrm{p}}$ & $h_{1}=-1$ & $h_{2}=4$ & $h_{3}=1$ & & \\
\hline
\end{tabular}

In this case, the total cost will be obtained as follows:

Total cost $=(3 * 20)+(4 * 15)+(8 * 20)+(4 * 60)+(1 * 35)=$ Rs. 555

Thus, this routing technique has also managed to meet all the demand/supply requirements as it entails $5(=\mathrm{x}+\mathrm{y}-$ $1=3+3-1)$ transportations as occupied cells are 5 .

\section{Conclusion}

This paper considered optimization techniques of transportation problem for three variables using four methods. Optimization of problems is the same as choosing optimal solution from the available alternatives. As evidenced from previous researches, this technique is applicable in a wide range of fields. However, MODI method employed in this paper can be used with good deal of success in solving such problems. This is because while working hand in hand with the remaining three methods, MODI method computed the optimal solution within a shorter period of time. Besides, it reduced complexities via producing a simple and clear solution that could be easily used in other areas for optimizing other problems.

\footnotetext{
${ }^{3}$ Northwest corner, Vogel or least cost
} 


\section{Journal Papers:}

\section{References}

[1] Ahmad, Hlayel Abdallah. "The Best Candidates Method for Solving Optimization Problems." Journal of Computer Science , 2012: 711-715

[2] Atoum, J. "Solving the traveling salesman problem using new operators in genetic algorithms." Journal of applied sciences, 2009: 1586-1590.

[3] Ech-Cherif, A. "A new machine learning based approach for tuning metaheuristics for the solution of hard combinatorial optimization problems." ournal of applied sciences, 2010: 1991-2000.

[4] Soewono, E. "Oil production optimization in a cluster of gas lift wells system." journal of applied sciences, 2010: 1705-1713.

[5] Tlelo-Cuautle, E. "Applications of evolutionary algorithms in the design automation of analog integrated circuitsournal ." journal of applied sicences, 2010: 1859-1872.

[6] Lu, H. "A new particle swarm optimization with a dynamic inertia weight for solving constrained optimization problems." inform technolofy journal of applied sciences, 2010: 1536-1544.

[7] Djebbar, B. "Optimization of a quadratic function under its canonical form." Asian journal of applied sciences, 2009: 499-510.

[8 ] Mahad, D.A. "Modeling of multi-level capacitated lot-size scheduling problem." journal of applied science, $2011: 290-296$.

[9] Alimohamadi, A. "Routing of water pipeline using gis and genetic algorithm." Journal of applied science, 2009: 4137-4145.

[10] Chaudhuri, Arindam. "A Comparative study of Transportation Problem under." Journal of mathematics and computer science, 2011: 256-267.

[11] Araghi, S.A., M. "An application of combined model for tehran metropolitan area incorporating captive travel metropolitan area incorporating captive travel." journal of applied sciences, 2009: 64-74.

[12] Mayo, A. "A semantic-based genetic algorithm for sub-ontology evolution. Inform." journal of applied sciences, 2009: 609-620.

Books:

[1] Burkard, R.E. assignment problems. Philadelphia: SIAM, 2009.

[2] Putcha, Aditya K. "SPECIAL CASES OF LP PROBLEM." INDR 262 Optimization Models and Mathematical Programming, 2010: 1234-1240.

[3] Turkey, Mertin. "NEW ALTERNATE METHODS OF TRANSPORTATION." traansportation problem, 2008: 1008-1012. 